\title{
Audit of caesarean section for non-progress of labor
}

\section{Tripti Singh Kathuria*, Rekha Sapkal}

Department of Obstetrics \& Gynecology, Peoples Medical College and Research Centre, Bhopal, Madhya Pradesh, India

Received: 09 March 2016

Revised: 15 March 2016

Accepted: 28 March 2016

\section{*Correspondence:}

Dr. Tripti Singh Kathuria,

E-mail: dr.tripti87@gmail.com

Copyright: (c) the author(s), publisher and licensee Medip Academy. This is an open-access article distributed under the terms of the Creative Commons Attribution Non-Commercial License, which permits unrestricted non-commercial use, distribution, and reproduction in any medium, provided the original work is properly cited.

\section{ABSTRACT}

Background: There is alarming increase in the number of caesarean section in the recent past years and many of the indications are due to non-progress of labor. The aim of the present study is to evaluate various parameters and associated factors responsible for non-progress of labor and to study the neonatal outcome.

Methods: Retrospective analysis of 42 emergency cases leading into caesarean section for non-progress of labor was done. Factors like age, parity, gestational age, duration of prolong labor, maternal and neonatal outcome was analyzed.

Results: In our study mean age of the women who underwent caesarean section for non-progress of labor was 25 years \pm 2.26 . When the duration of labor was analyzed, maximum cases i.e. $60 \%$ non-progress of labor is seen in active phase, $30 \%$ cases had prolonged latent phase of labor, arrest of descent in $10 \%$.There were 14 babies who were shifted to NICU, out of them 10 babies had Apgar score <7. Average baby weight was 2689 grams \pm 446.60 . Median range of birth weight was 2800 grams.

Conclusions: Maximum cases $60 \%$ were in active phase, $10 \%$ with non-progress in second stage of labor. Out of total cases, 33\% of newborns had NICU admission, out of them 16\% had poor Apgar score but rate of NICU admission due to non-progress of labor remained same. Hence early decision making in caesarean section will help in preventing neonatal complication. There was no neonatal mortality observed in the study.

Keywords: Non progress of labor, Caesarean section, Neonatal outcome

\section{INTRODUCTION}

There is alarming increase in the incidence of caesarean section now days, for non-reassuring fetal status and to avoid future medico legal complications. ${ }^{1}$ Caesarean section may be required in different clinical stages and phases of labour. Hence timely decision making is required. Labour is said to be prolonged when the combination duration of first and second stage is more than the arbitrary time limit of 18 hours.

Labour is considered prolonged when the cervical dilatation rate is less than $1 \mathrm{~cm}$ per hour for a period of minimum 4 hours observation (WHO 1994). ${ }^{2}$ The prolongation may be due to protracted cervical dilatation in first stage or inadequate descent of presenting part during first or second stage of labor. ${ }^{3}$

Hence there is a need to explore status of the patient during and after the caesarean section in labour. This study provides the critical review for caesarean section done for non-progress of labour. Identification of nonprogress of labour is crucial so that its proper evaluation and management can result in favourable outcome. Nonprogress of labour can take fatal turn for baby as well as mother. 


\section{Aim \& objective}

The aim of the present study is to evaluate various parameters responsible for non-progress of labor and neonatal outcome. The research question of the study was, what are the reasons for non-progress of labor leading into caesarean section, associated factors were explored. Maternal and fetal effects of due to nonprogress of labor were analyzed.

\section{METHODS}

Retrospective case record analysis of the obstetric outcome in 42 patients who underwent caesarean section for non-progress of labour was undertaken. It was carried out at PCMS for period of one year from June 2013-June 2014; among all confinements those patients who had caesarean section due to non-progress of labour were included. Demographic variables like age, parity, gestational age, various maternal high risk factors, duration of prolong labour, need for caesarean section in latent or active or second stage of labour were analysed, type of abnormal labour was predicted by documentation of pantograph. Additional coexistent fetal reasons for caesarean section were also recorded. Neonatal condition at birth and need of NICU admission was analysed. This study included all patients with Singleton pregnancy, Cephalic presentation, adequate pelvis, good fetal heart rate. Distribution parameters were expressed in terms of their mean value and Standard deviation.

\section{RESULTS}

In our study mean age of the women who underwent caesarean section for non-progress of labour was 25 years \pm 2.26 modes \& median value 26 years (Figure 2). Only $21 \%$ belong to rural strata, majority of women belonged to urban strata $79 \%$ (Figure 1). Among them $35(83 \%)$ patients were primi gravida, second gravida were $10 \%$, in $7 \%$ cases parity was more than two. Majority of cases $(21 \%)$ were of gestational age 38 weeks \pm 2.29 . When the duration of labour was analysed, In maximum cases i.e.60\% non-progress of labour was seen in active phase, next in the series was prolonged latent phase of labour i.e. $30 \%$. $10 \%$ of cases were documented with arrest of descent (Table 2). Majority of the primigravida had arrest of labour during first stage of labour, $p$ value (0.016), which was found to be statistically significant. On analysing associated risk factors for prolonged labour, anemia was observed in 10 (24\%) cases, IUGR and oligoamnios were observed in 9 (21\%) cases, GDM and cases with postdatism were 5 (12\%). Others cases like post maturity, PIH, hypothyroidism, $\mathrm{RH}$ iso-immunization together were $8 \%$. Out of number of complications PPH was the most common i.e. $7.1 \%$. Post-operative morbidity was observed in the form of febrile episode $(5.25 \%)$, wound sepsis or dehiscence $(3 \%)$, UTI (3\%) (Figure 3). These were the common problem recorded. Average hospital stay was 8 days.

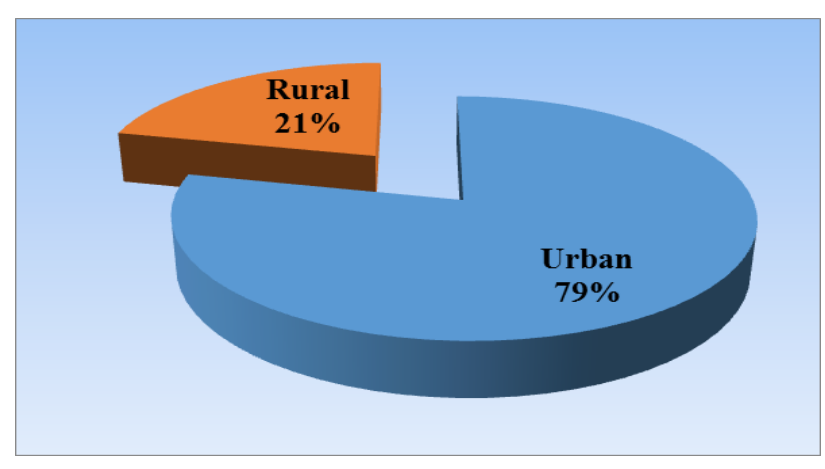

Figure 1: Distribution of study subjects according to socio economic status.

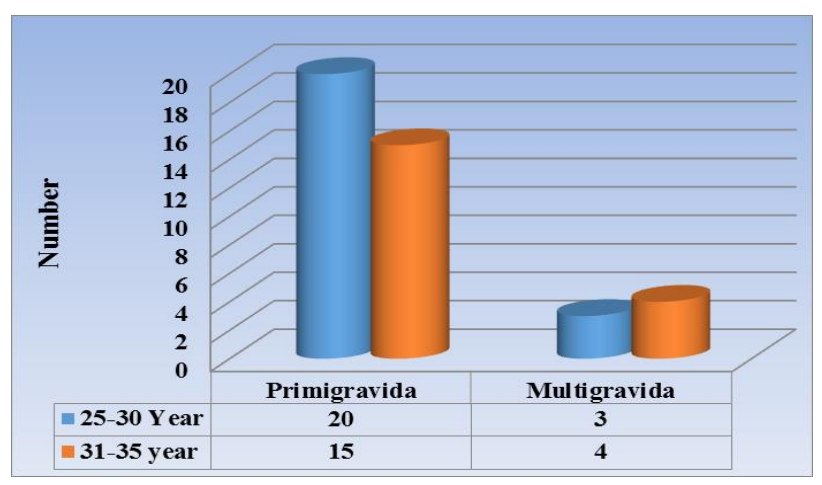

Figure 2: Distribution of study subjects according to age \& Gravida.

Table 1: Distribution of subjects according to parity and stage of labour $(n=42)$.

\begin{tabular}{|llll|}
\hline $\begin{array}{l}\text { Stage of } \\
\text { labour }\end{array}$ & Primigravida & Multigravida & Total \\
\hline $1^{\text {st }}$ stage & 34 & 5 & 39 \\
\hline $2^{\text {nd }}$ stage & 1 & 2 & 3 \\
\hline Total & 35 & 7 & 42 \\
\hline $\begin{array}{l}\text { Chi square } \\
\text { value }\end{array}$ & 5.82 & & \\
\hline P value & $0.016(\mathrm{~S})$ & & \\
\hline
\end{tabular}

Table 2: Distribution of subjects according to prolong stages of labour $(n=42)(\%)$.

\begin{tabular}{|c|c|}
\hline Stage of labour & Number of cases $(n=42)(\%)$ \\
\hline Prolong first stage & \\
\hline Prolong latent phase & $12(30 \%)$ \\
\hline Prolong active phase & $26(60 \%)$ \\
\hline Prolong second stage & $4(10 \%)$ \\
\hline
\end{tabular}

Neonatal outcome after this caesarean section in form of new born agar score at birth and birth injuries were documented. There were 14 NICU admissions, 5 minute Apgar was less than seven in 10 new borns, and $\mathrm{P}$ value was 0.3 which was not statistically significant (Table 3 ). Among them Female new born were 55\% and male were $50 \%$. Average baby weight was 2689 grams \pm 446.60$)$. Median range of birth weight was 2800 grams (Figure 3). 


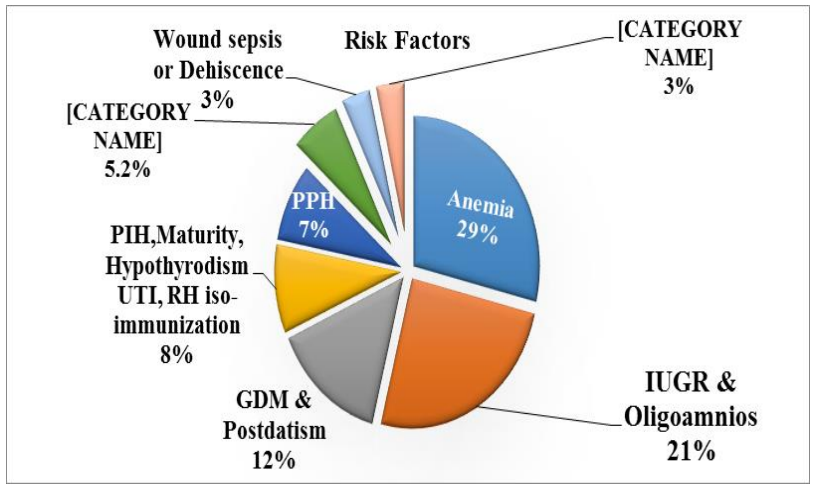

Figure 3: Various maternal risk $M$ factors associated with prolong labour.

Table: 3 Distribution of neonates according to APAR score $(n=42)$.

\begin{tabular}{|llll|}
\hline Time & $\begin{array}{l}\text { APGAR } \\
\text { score }>7\end{array}$ & $\begin{array}{l}\text { APGAR } \\
\text { score }<7\end{array}$ & Total \\
\hline $1^{\text {st }}$ minute & 28 & 14 & 42 \\
\hline $5^{\text {th }}$ minute & 32 & 10 & 42 \\
\hline Chi square value & 0.933 & & \\
\hline P value & 0.33 & & \\
\hline
\end{tabular}

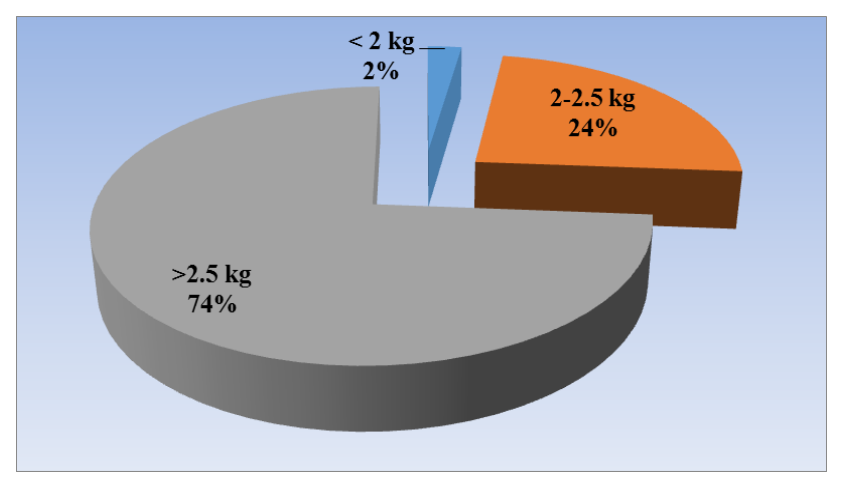

Figure 4: Distribution of new borns according to baby weight.

\section{DISCUSSION}

In present study nullipara with prolong second stage of labour were $2.8 \%$, while multigravida were $28 \%$, however in the study conducted by Victoria M Allen, et al $(14.8 \%)$ of nulliparous women \& (13.2\%) of multiparous women identified as having prolong second stage of labour. ${ }^{3}$ So prevalence of prolong second stage of labour was same in primigravida and multigravida

In the present study with sample size of 42 , maximum cases had protracted active stage of labour (50\%), followed by prolong latent phase i.e. $30 \%$, lastly $20 \%$ had prolonged second stage of labour. In the study conducted by Deidre spelliscy, et al with sample size of $2447,24 \%$ of these cesareans were done for prolong latent phase of labour, $53 \%$ for protracted second stage of labour and the remaining $23 \%$ for prolong second stage of labour, thus the results were similar to our study. ${ }^{4}$

In our study latent phase prolongation for nullipara was 21 hours and for multipara was about 12 hours, Similarly in the study conducted by Deidre $\mathrm{S}$, et al the average length of labour for nulliparas with cesareans done in latent phase was 16.0 hours, for multiparas 12.4 hours. $^{4}$

$\mathrm{PPH}$ is one of the observed complication with prolong labour. In the present study atonic PPH was $7.1 \%$, traumatic PPH was not seen, may be because of the early surgical interference It may be due to atonicity of uterus as it gets exhausted \& perineal injuries because of prolong pressure of the presenting part .In a study conducted by Myles, Thomas D. Santolaya, Joaquin, et al he concluded that cases with prolonged second stage of labour had complication like, PPH 6\%.5 Associated condition GDM as seen in $12 \%$ in our study and in their study it was $9 \%$. Difference in their and present study is that they have conducted the study exclusively on prolong labour in second stage; our study was conducted in both first and second stage of labour.

Increasing baby weight may be one of the factor for nonprogress of labour in second stage, however In the present study mean weight was $2.8 \mathrm{~kg}$. This observation is similar to study conducted by Victoria metal. ${ }^{6}$ In their study they concluded mean weight of babies with prolong second stage were $2.9 \mathrm{~kg}$ or more than that. Out of a total $14(34 \%)$ NICU admission poor Apgar score was found in $(24 \%)$ babies out of them $30 \%$ of babies with poor Apgar score belong to group with prolong latent phase of labour. In the study conducted by Maghoma J. Buchmann EJ, he conducted pregnancy cohort study to assess the fetal, maternal and obstetric risks associated with the prolonged latent phase of labour. ${ }^{1,7}$ 5-minute Apgar scores less than $7(17 \%)$ and admission to the neonatal unit $(22 \%)$.

\section{CONCLUSIONS}

Among the cases of non-progress of labour that ended up into caesarean section, majority $60 \%$ had non-progress of labour in the active phase. Next in order was nonprogress in latent phase i.e. $30 \%$. In short in majority of cases caesarean section is required for prolong first stage of labour. Among them $38 \%$ had induced labour. There was no change for need of NICU admission with prolong labour. Hence early decision making in caesarean section will help in preventing neonatal complication. There was no neonatal mortality observed in the study. Increased clinical skill and a good documentation of the progress of labour in birth records are of great importance to identify and classify prolonged labour, careful management of interventions is crucial in order to keep normal births normal and avoid mistreatment. 


\section{Impact of study}

There is more chance of non-progress labor in first stage especially with induction of labor, non-progress of labor is more in is more in primigravida. Need of the caesarean section is more in first stage thus critical observation of the patient in first stage is important. Careful monitoring in first stage is also important for neonatal outcome. Predicting the reasons and associated factors with nonprogress of labor help in reducing the maternal and fetal morbidity; this analysis will provide us with a protocol to formulate preventive measures in future.

Limitations of the study was to sample size is small and it was a retrospective study so certain factors, could not be recorded due to unviability of records.

\section{ACKNOWLEDGEMENT}

I would like to thank Dr. Anjali Kanhere to help me throughout this study showing me the way to progress.

Funding: No funding sources

Conflict of interest: None declared

Ethical approval: The study was approved by the Institutional Ethics Committee

\section{REFERENCES}

1. William PD, Choate JW, Nusbaum M, Mccarthy MA, Margaret R, Mortimer G et al. Obstetric care and cesarean birth rates: a program to monitor quality of care. Audit of caesarean section for nonprogress of labor. 1992;80:5.
2. Dutta DC, Konar H. Textbook of obstetrics, perinatology and contraception. 2004;6:402.

3. Allen VM, Baskett TF, O'Connell CM, McKeen D, Allen AC. Maternal and perinatal outcomes with increasing duration of the second stage of labor. Obstet Gynecol. 2009;113(6):1248-58.

4. Gifford D, Spelliscy M, Fiske SC, Keesey M, Keeler J, Kahn K. Lack of progress in labor as a reason for cesarean. Obstetr Gynecol. 2000;95(4):589-95.

5. Thomas MD, Joaquin S. Maternal and neonatal outcomes in patients with a prolonged second stage of labor. department of obstetrics and gynecology, Saint Louis University, St. Mary's Health Center, St. Louis, Missouri; and Department of Obstetrics and Gynecology, Texas Tech Health Sciences Center, Amarillo, Texas. 2003;102:52-58.

6. Allen VM, Baskett TF, O'Connell CM, McKeen D, Allen AC. Maternal and perinatal outcomes with increasing duration of the second stage of labor. Department of Obstetrics and Gynecology, Dalhousie University, Halifax, Nova Scotia, Canada. 2009;113(6):1248-58.

7. Maghoma J, Buchmann EJ. Maternal and fetal risks associated with prolonged latent phase of labor. Department of obs \& gynae Chris Hani Baragwanath Maternity Hospital, Soweto, South Africa. 2002;22(1):16.

Cite this article as: Kathuria TS, Sapkal R. Audit of caesarean section for non-progress of labor. Int J Reprod Contracept Obstet Gynecol 2016;5:1002-5. 